\begin{tabular}{|c|l|}
\hline Title & $\begin{array}{l}\text { Influence of Liquid Properties and Operating V ariables on Enrichment Ratio in Nonfoaming and Foaming A dsorptive } \\
\text { Bubble Separation Techniques }\end{array}$ \\
\hline Author(s) & Suzuki, A kira; Maruyama, Hideo \\
\hline Citation & $\begin{array}{l}\text { Journal of Colloid and Interface Science, 238(1),54-61 } \\
\text { https:/doi.org/10.1006/cis.2001.7492 }\end{array}$ \\
\hline Issue Date & 2001-06-01 \\
\hline Doc URL & http://hdl.handle.net/2115/8525 \\
\hline Type & article (author version) \\
\hline File Information & suzuki_maruyama_01_JCIS.pdf \\
\hline
\end{tabular}

Instructions for use 


\title{
INFLUENCE OF LIQUID PROPERTIES AND OPERATING VARIABLES ON ENRICHMENT RATIO IN NONFOAMING AND FOAMING ADSORPTIVE BUBBLE SEPARATION TECHNIQUES
}

\author{
Akira SUZUKI ${ }^{*}$ and Hideo MARUYAMA \\ Laboratory of Bioresources Chemistry, Division of Marine Biosciences, \\ Graduate School of Fisheries Sciences, Hokkaido University, Minato \\ 3-1-1, Hakodate, 041-8611, JAPAN. \\ TEL: +81+138+40+8811; FAX: +81+138+40+8811; E-mail: \\ suzuki@elsie.fish.hokudai.ac.jp. \\ Keywords: Nonfoaming Adsorptive Bubble Separation; Foam Separation; \\ Dimensionless Correlation; Enrichment ratio; Ohnesorge number \\ * Corresponding to the author
}




\begin{abstract}
\end{abstract}
The influence of the liquid properties and the operating variables on the intrinsic volumetric flow rate, $q_{0}$, of the droplets at the liquid-atmosphere interface in nonfoaming adsorptive bubble separation and that, $W_{\mathrm{f} 0}$, of the liquid in foam at the liquid-foam interface in foam separation was studied to estimate the enrichment ratio of surface-active substance in the both techniques. Each intrinsic flow rate was determined by the extrapolation method, which the authors proposed previously, and was mainly influenced by superficial gas velocity, liquid viscosity and surface tension. Despite of small change in the surface tension and the liquid viscosity, they greatly affected to the intrinsic flow rate for both the droplets and the liquid in foam. The experimental results were applied to a dimensional analysis. Dimensionless volumetric flow rates, $q_{0} / Q$ and $W_{\mathrm{fo}} / Q$, were successfully correlated with a dimensionless number (Ohnesorge number, $Z=\mu_{\mathrm{L}} /\left(\rho_{\mathrm{L}} \sigma\right.$ $\left.\left.d_{\mathrm{b}}\right)^{0.5}\right) \cdot q_{0} / Q=6.66 Z^{1.46}$ and $W_{\mathrm{fo}} / Q=2.53 Z^{0.533}$ were obtained for the nonfoaming and the foaming regions within errors 30 and $35 \%$, respectively. The enrichment ratio of surface-active substance in the 
droplets and the liquid in foam to the bulk liquid was derived from using these correlations for the nonfoaming and the foaming regions, respectively. A good agreement of the experimental enrichment ratio and the calculated ones was obtained by using the correlations for nonfoaming and foaming. 


\section{INTRODUCTION}

Adsorptive bubble separation techniques are divided unequally into two main groups. The major, called foam separation, requires the generation of foam or froth to carry off the objective substances. The minor, which is termed nonfoaming adsorptive bubble separation (NFBS), does not. The foam separation has been widely used in various industrial fields such as ore flotation, wastewater treatment and so on. On the other hand, the initial concept of NFBS method was proposed by Lemlich and his co-workers in early 1960s (1-3). The authors reported the application of the developed NFBS method to the enrichment of dissolved organic substances from their dilute solutions by using a bubble column equipped with a droplet collector at the top of the column and the mechanism of the enrichment $(4,5)$. Both two techniques are available for the enrichment of dilute dissolved surface-active substances and have some advantages, i.e., low energy requirements, a little mechanical parts in the apparatus, no-requirement of tedious treatments such as desorption or addition of any other chemicals and extending to a continuous operation with ease. 
In the adsorptive bubble separation techniques, the adsorption density on the bubble surface (surface excess) has been often determined from the mass balance of the separation column (6-9). On the other hand, the volumetric flow rate and the concentration of the droplets and the collapsed foam liquid had an axial distribution with the column height (5, 10-12). These facts suggested that the amount of the adsorbate contained in the droplets and the collapsed foam liquid would vary with the capturing or the overflowing positions in the axial direction within the column $(5,12)$. The authors demonstrated the measurements of their axial profiles and determined the intrinsic values by the extrapolating method $(5,12)$. Moreover, the adsorption density onto the bubble surface was determined from the mass balance of the objective substances between the droplets or the collapsed foam liquid and the bulk liquid in the column $(5,12)$.

The factors governing the enrichment efficiency of the two techniques would be considered as: (i) the physicochemical properties of the objective surface-active substance and (ii) the liquid properties and the operating variables for both methods. The two factors affected the absorbability of the objective substance onto bubble surface, the bubble production 
frequency and the entrained or overhead liquid flow rate.

The estimation of the adsorption parameter of the objective substance, the bubble production frequency and the entrained or overhead flow rate would be very important to predict the enrichment efficiency. Figure 1 shows schematic diagrams of the mass balance of surface-active substance in NFBS and foam separation columns. In NFBS and foam separation methods, the enrichment ratios at the liquid-atmosphere and the liquid-foam interfaces are defined by the following two equations, respectively $(5,12)$.

$$
\begin{aligned}
& E_{\mathrm{N}} \equiv C_{\mathrm{tr}} / C_{\mathrm{i}}=1+\left(S_{\mathrm{b}} / q_{0}\right)\left\{K \gamma /\left(1+K C_{\mathrm{i}}\right)\right\}, \\
& E_{\mathrm{F}} \equiv C_{\mathrm{f} 0} / C_{\mathrm{i}}=C_{\mathrm{b}} / C_{\mathrm{i}}+\left(S_{\mathrm{b}} / W_{\mathrm{f} 0}\right)\left[K \gamma C_{\mathrm{b}} /\left\{\left(1+K C_{\mathrm{b}}\right) C_{\mathrm{i}}\right\}\right] .
\end{aligned}
$$

Where $C_{\mathrm{i}}, C_{\mathrm{b}}, C_{\mathrm{fo}}$ and $C_{\mathrm{tr}}$ are the initial concentration of the bulk liquid, the concentration of the bulk liquid at equilibrium, the concentration of the liquid in foam at the liquid-foam interface and the concentration of the droplets, respectively. $q_{0}$ and $W_{\mathrm{f} 0}$ are the intrinsic volumetric flow rate of the droplets at the liquid-atmosphere interface and the liquid in foam at the 
liquid-foam interface. $K$ and $\gamma$ represent the adsorption equilibrium constant and the saturated surface density of the bubble surface, which could be determined from the Langmuir`s plot $(5,12) . S_{\mathrm{b}}$ denotes the production rate of the bubble surface area and was determined from the relationship (4).

$$
S_{\mathrm{b}}=6 A \varepsilon(1-\varepsilon)^{4.65}\left\{(4 / 225)\left(\rho_{\mathrm{L}}-\rho_{\mathrm{G}}\right)^{2} g^{2} /\left(\mu_{\mathrm{L}} \rho_{\mathrm{L}}\right)\right\}^{1 / 3} .
$$

Where $A, \varepsilon, g, \rho_{\mathrm{L}}, \rho_{\mathrm{G}}$ and $\mu_{\mathrm{L}}$ represent the cross-sectional area of the column, the gas holdup, the gravitational acceleration, the density of liquid and gas and the viscosity of the liquid, respectively. Eqs. [1] and [2] are analogous forms. In Eqs. [1] and [2], the terms $K \gamma /\left(1+K C_{\mathrm{i}}\right)$ and $K \gamma C_{\mathrm{b}}$ $/\left\{\left(1+K C_{\mathrm{b}}\right) C_{\mathrm{i}}\right\}$ represent the influence of the physicochemical properties of the objective substance adsorbed on the bubble surface. The other terms, $\left(S_{\mathrm{b}} / q_{0}\right)$ and $\left(S_{\mathrm{b}} / W_{\mathrm{f} 0}\right)$, would be affected by both liquid properties and the operating variables. These equations also suggest that each enrichment ratio gets larger as the two terms increase. In other words, better operating variables to make the enrichment ratio much higher will be compatible with 
the determination of how to keep $q_{0} / S_{\mathrm{b}}$ and $W_{\mathrm{fo}} / S_{\mathrm{b}}$ smaller.

In the present paper, the authors will discuss the influence of the liquid properties and the operating variables on the enrichment ratio for both the nonfoaming and the foaming adsorptive bubble separation methods. 


\section{MATERIALS AND METHODS}

\section{Materials}

Glycerin (Gly), crystal violet (CV), sodium dodecyl benzene sulfate (SDBS), sodium decanoate (C10), sodium octanoate (C8), hemoglobin from bovine (HB) and sodium dodecyl sulfate (SDS) were purchased from Wako Pure Chemical Industries Ltd. (Japan). Egg ovalbumin (OA) was purchased from Eastman Kodak Company or Difco Laboratories. Humic acid (HA) was purchased from and Aldrich Chemical Company, Inc.

In these chemicals, Gly, CV, C8, C10, SDS, HA and OA were used in nonfoaming experiments. SDBS, $\mathrm{HB}$ and $\mathrm{OA}$ were used in foaming experiments. Glycerin solutions contained $1 \mathrm{wt} \% \mathrm{NaCl}$. Protein solutions contained $5 \times 10^{-3} \mathrm{M} \mathrm{NaCl}$ and the $\mathrm{pH}$ were adjusted with aqueous $\mathrm{HCl}$ or $\mathrm{NaOH}$ solutions. All the chemicals were used without further purifications.

Experimental setup for nonfoaming experiments

The experimental setup for NFBS method is shown in figure 2. The setup is almost the same as those used in the previous report (5). A bubble 
column consisting of a cylindrical acrylic resin tube of $4.4 \times 10^{-2} \mathrm{~m}$ I.D. and $0.36 \mathrm{~m}$ in height was constructed. Sintered glass filter, which had pores of $10 \times 10^{-6}-15 \times 10^{-6} \mathrm{~m}$ in the mean diameter (G4), was installed as gas distributor at the bottom of the column. Another sintered glass filter, whose the mean pore diameter ranging from $40 \times 10^{-6}$ to $100 \times 10^{-6} \mathrm{~m}$ (G3), was also used if necessary. Nitrogen gas or air was supplied to the column through a distributor. Pressure taps for measuring gas holdup in the column were installed at intervals of $0.25 \mathrm{~m}$ along the wall.

The droplet trap and the droplet collector were used to measure the volumetric flow rate, $q$, and to determine the concentration, $C_{\mathrm{tr}}$, of the droplet, respectively. They were equipped at the top of the column when they were used. The droplet trap (figure 2) was made of acrylic cylinder with a steel mesh at the bottom end. During the experiment, the trap was filled with a certain amount of cotton to entrap droplets generated at the liquid-atmosphere interface. The detailed drawing of the collector is shown in figure 3 (4). The droplet collector was made of transparent plastic resin and was consisted of a conical upper section with a cone angle of $75^{\circ}$ and a cylindrical lower section with a diameter of $50 \times 10^{-6} \mathrm{~m}$ and a height of 32 
$\times 10^{-3} \mathrm{~m}$. A suction tap of stainless steel pipe $\left(0.3 \times 10^{-6} \mathrm{~m}\right.$ in inside diameter) was attached to the top of the cone and it was connected to a reservoir for droplet recovery. To minimize droplet drying, four glass tubes were installed at the wall of the cylindrical part to induce humidified air.

Experimental setup for foaming experiments

The experimental setup for foaming experiment is also almost the same as that described in the literature (12) and shows in figure 4. A bubble column consisting of a cylindrical acrylic resin tube of $4.4 \times 10^{-2} \mathrm{~m}$ I.D. and 0.6 or $0.95 \mathrm{~m}$ in height was constructed. A sintered glass filter, whose mean pore diameter ranging from $10 \times 10^{-6}$ to $15 \times 10^{-6} \mathrm{~m}(\mathrm{G} 4)$, was used as a gas distributor. Nitrogen gas was supplied to the column through the distributor. The foam collector (figure 4) was equipped at the top of the column to entrap the liquid in foam generated from the liquid surface within the column. Pressure taps for measuring gas holdup in the column were installed at intervals of $0.25 \mathrm{~m}$ along the wall.

Procedure for measurement of volumetric flow rate and concentration of 
droplet in nonfoaming

Glycerin, CV, C10, C8, SDS and OA were used for nonfoaming experiment. An experimental procedure for measuring volumetric flow rate of droplets was carried out as follows. A solution contained a surface-active substance was prepared at a desired concentration and was charged into the column up to a desired liquid level. Then, aeration was started and the trap was exposed to the upward flow of droplets generated at the liquid surface. After a certain time, the trap was detached from the column and it was weighed with a balance. The volumetric flow rate, $q$, of droplets was determined from the change in weight of the trap and the exposure time, assuming that the density of solution was equal to that of water. The experiments were repeated at various distance $H$ (figure 2) between the bottom of the droplet trap (or the droplet collector) and the liquid surface. The intrinsic flow rate, $q_{0}$, of droplet at the liquid-atmosphere interface within the column was determined by the extrapolation method using the axial profile of $q$ (5).

The experiments for determination of droplet concentration were carried out as follows. A solution was prepared at a desired concentration 
and it was charged into the column. After that, air or nitrogen gas were dispersed into the column and the aspiration for droplet collection was started. A lot of fine droplets generated by bubble burst at the liquid surface were induced into a sampling reservoir by the aid of air stream through aspirator. To avoid the error caused by sample drying, another reference reservoir was connected with the sampling one in series. An equal amount of distilled water was placed in the both. The volume of sampled liquid was calibrated by the volume decrease of precharged water in the reference. Each run was conducted for 30 minutes. As the preliminary experiments showed that $C_{\text {tr }}$ was not changed with the position of the collector in the range of $1.4 \times 10^{-2}-4.4 \times 10^{-2} \mathrm{~m}$, all the experiments were carried out at the constant position of $2.4 \times 10^{-2} \mathrm{~m}$. The authors assumed this system as a pseudo-steady state because change in the initial concentration was not observed.

Procedure for measurement of volumetric flow rate of liquid in foam

The procedure for measuring the flow rate of the liquid in foam was the same as it described in the previous study (12). SDBS, HB and OA were 
used in foaming experiments. The solution prepared at a desired concentration was stored in a storage tank. The solution was charged into the column from a feed tap by a pump. The volumetric flow rate of feed liquid was $5.0 \times 10^{-7} \mathrm{~m}^{3} / \mathrm{s}$. After the column was filled with the solution, nitrogen gas was supplied and was dispersed as bubbles by the distributor. The foam height, which corresponds to the distance between the liquid foam interface and the column top within the column, was adjusted by control of the volumetric flow rate of the drain liquid using a rotameter. The bulk liquid in the column was sampled at the bottom of the column. After a steady state condition was attained for ca. two hours, the samplings of the foam liquid for measuring the volumetric flow rate, $W_{\mathrm{f}}$, and the concentration, $C_{\mathrm{f}}$, were started. The volumetric flow rate of liquid in the foam was measured as follows. The collector was attached on the top of the column and was exposed to the upward flow of foam generated from the liquid surface. After ca. 15 seconds, the collector was detached from the column and was weighted on a balance. This procedure was repeated five times using five collectors (for ca. six minutes). The volumetric flow rate, $W_{\mathrm{f}}$, of liquid in the foam was determined from the change in the sum of the 
weight of the collectors and the exposure time, assuming that the density of the liquid in the foam was nearly equal to that of water. After changing the foam height, the experiments were repeated. The intrinsic flow rate, $W_{\mathrm{f} 0}$, and the concentration, $C_{\mathrm{f} 0}$, of the liquid in the foam within the column were determined by the extrapolation method (12).

Determination of liquid properties and gas holdup

Liquid viscosity was measured by Ostwald viscosity meter. Surface tension was measured by the ring method using du Noüy meter. Gas holdup was measured in the same manner described in the previous papers (4-5, 12) as follows. The gas holdup was determined from the difference in static pressure between the clear and aerated liquids using a differential pressure transducer (Tem Tech). Voltage signals were recorded by a personal computer (NEC PC-9801VM) via A/D convertor (CONTEC).

Determination for concentration of solution

The concentration of $\mathrm{CV}$ and $\mathrm{HA}$ were measured spectrophotometrically at 600 and $300 \mathrm{~nm}$, respectively. The concentrations 
of the proteins (OA and $\mathrm{HB}$ ) were measured by the Lowry method (13). The $\mathrm{pH}$ of the bulk liquid in the column was measured with a $\mathrm{pH}$ meter (ORION Model SA 520). 


\section{RESULTS AND DISCUSSION}

Influence of liquid properties and operating variables on volumetric flow rate of the droplets and the liquid in foam and the gas holdup

As typical experimental results, figures 5 and 6 show change in the intrinsic volumetric flow rate of droplets, $q_{0}$, and liquid in foam, $W_{\mathrm{f} 0}$, and gas holdup, $\varepsilon$, with superficial gas velocity, $U_{\mathrm{g}}$. Both $q_{0}$ and $W_{\mathrm{f} 0}$ increased with increasing $U_{\mathrm{g}}$ and concentration of glycerin and sodium dodecyl benzene sulfate (SDBS) for nonfoaming and foaming. $U_{\mathrm{g}}$ obviously influenced to $q_{0}$ and $W_{\mathrm{f} 0}$. Change in concentration of glycerin and SDBS correspond to variation of liquid viscosity and surface tension. Influence of these liquid properties was discussed in the following.

Figures 7 and 8 show the influence of the surface tension (figure 7) and the liquid viscosity (figure 8) on the intrinsic volumetric flow rate of the droplets, $q_{0}$, and the liquid in foam, $W_{\mathrm{f} 0}$, and the gas holdup, $\varepsilon$. The tendency of the relationships between the production rate, $S_{\mathrm{b}}$, of the bubble surface area and the liquid viscosity and the surface tension were almost the same as figure 8 . These data are not shown. The viscosity and the 
surface tension of the solutions were varied from $9.0 \times 10^{-4}$ to $1.14 \times 10^{-3}$ $\mathrm{kg} /(\mathrm{m} \mathrm{sec})$ and from $6.54 \times 10^{-2}$ to $7.21 \times 10^{-2} \mathrm{~N} / \mathrm{m}$, respectively. In figures 7 and 8 , concentration ranges of each substance were as follows: $1.7 \times 10^{-4}$ $1.0 \times 10^{-1} \mathrm{~kg} / \mathrm{m}^{3}$ for OA, $5 \times 10^{-3}-1.5 \times 10^{-2} \mathrm{~kg} / \mathrm{m}^{3}$ for $\mathrm{CV}, 5.21 \times 10^{-3}-$ $2.61 \times 10^{-1} \mathrm{~kg} / \mathrm{m}^{3}$ for $\mathrm{C} 10,6.44 \times 10^{-3}-2.16 \times 10^{-2} \mathrm{~kg} / \mathrm{m}^{3}$ for SDBS, $10.1-$ $52.6 \mathrm{~kg} / \mathrm{m}^{3}$ for Gly and $1.74 \times 10^{-2} \mathrm{~kg} / \mathrm{m}^{3}$ for SDS. $q_{0}, W_{\mathrm{f} 0}$ and $\varepsilon$ were greatly influenced by surface tension and liquid viscosity. In the vicinity of $6.5 \times 10^{-2} \mathrm{~N} / \mathrm{m}$ for surface tension, an apparent boundary between both region of the nonfoaming and the foaming was observed (figure 7a). The volumetric flow rate decreased abruptly from the foaming to the nonfoaming region. However, such a boundary was not recognized in figures $7 \mathrm{~b}, 8 \mathrm{a}$ and $8 \mathrm{~b}$. The reason was considered as follows. Bubbles were generated in the bulk liquid (the dispersed phase). The gas holdup was reflected by the bubble size distribution and the frequency in the liquid pool. However, the droplets and the foam were generated at the liquid-atmosphere and the liquid-foam interfaces within column, respectively. They would be affected by the behavior of the bubbles that reached at the interfaces. These should be caused by the stability or the 
rigidity of bubble surface reached at the interfaces. The coverage of bubble surface by surface-active substances might be related to the stability. In the case of proteins, $\mathrm{pH}$ values affected $W_{\mathrm{f} 0}$ (figure 8a). This fact should be considered that influence of $\mathrm{pH}$ on the adsorbability of proteins onto bubble surface (8). $W_{\mathrm{f} 0}$ for SDBS and OA (pH 4.6) were almost the same values of surface tension (ca. $5.25 \times 10^{-2} \mathrm{~N} / \mathrm{m}$ ). However, values of $\varepsilon$ for SDBS were higher than that of $\mathrm{OA}(\mathrm{pH} 4.6)$ in spite of the same surface tension range. As seen in figures 7 and 8, these influences on the liquid entrainments in droplet and liquid in foam seemed complicated. The authors will demonstrate the dimensional analysis to clarify these influences on the enrichment ratio in the NFBS and the foam separation techniques in the next section.

\section{Dimensional Correlation}

To clarify the influences of the liquid properties and the operating variables, the experimental results are applied to the dimensional analysis. The authors defined the dimensionless volumetric flow rate, $q_{0} / Q$, for nonfoaming and, $W_{\mathrm{f} 0} / Q$, for foaming, respectively. we assumed that the 
viscous and the surface tension force of liquid, the inertial force of bubbles and the gravity force at liquid-atmosphere and liquid-foam interfaces affected to the amount of entrained bulk liquid in droplet and liquid in foam at these interfaces. These were expected to be a function of three dimensionless terms as follows: $\mu_{\mathrm{L}} v_{\mathrm{b}} / \sigma, v_{\mathrm{b}}{ }^{2} \rho_{\mathrm{L}} / \sigma$ and $v_{\mathrm{b}}{ }^{2} /\left(g d_{\mathrm{b}}\right)$. These three terms are the Capillary number $(\mathrm{Ca})$, the Weber number $(\mathrm{We})$ and the Froude number $(F r)$, respectively. Where, the average bubble diameter, $d_{\mathrm{b}}$, and the terminal rising velocity of bubble swarms, $v_{\mathrm{b}}$, were calculated from:

$$
\begin{aligned}
& d_{\mathrm{b}}=U_{\mathrm{g}} /\left[\varepsilon(1-\varepsilon)^{4.65}\left\{(4 / 225)\left(\rho_{\mathrm{L}}-\rho_{\mathrm{G}}\right)^{2} g^{2} /\left(\mu_{\mathrm{L}} \rho_{\mathrm{L}}\right)\right\}^{1 / 3}\right], \\
& v_{\mathrm{b}}=U_{\mathrm{g}} / \varepsilon .
\end{aligned}
$$

Equation 4 was derived from the assumption that bubbles are homogeneous sphere and their terminal rising velocity can be calculated by Allen`s equation (14). An equation proposed by Lewis et al. was employed for voidage compensation (15). Least-square regression gave the following correlative equation for nonfoaming. 


$$
q_{0} / Q=5.9 \times 10^{-2} \mathrm{Ca}^{0.50} \mathrm{We}^{-0.024} \mathrm{Fr}^{1.3} .
$$

Then, Eq. [6] was summarized by the Bond number $\left(B o=\left(\rho_{\mathrm{L}}-\rho_{\mathrm{G}}\right) d_{\mathrm{b}}{ }^{2} g^{2} / \sigma\right)$ and the Reynolds number $\left(R e=d_{\mathrm{b}} v_{\mathrm{b}} \rho_{\mathrm{L}} / \mu_{\mathrm{L}}\right)$ and the least square regression gave the following equation.

$$
q_{0} / Q=0.54 B o^{0.57} R e^{-0.96}
$$

The ratio of the value of exponent of $B o$ to that of $R e$ can be approximated to $2 / 3$. $\rho_{\mathrm{G}}$ is negligible small than $\rho_{\mathrm{L}}$ in the present experimental conditions.

$$
B o^{2} / \operatorname{Re}^{3}=(225 / 4)^{1 / 3}\left(\mu_{\mathrm{L}} /\left(\rho_{\mathrm{L}} \sigma d_{\mathrm{b}}\right)^{0.5}\right)^{4 / 3}(1-\varepsilon)^{-4.65}
$$

The term $(1-\varepsilon)^{-4.65}$ can be regarded as 1 because the empirical values of $\varepsilon$ was very small in the present study. The term, $\mu_{\mathrm{L}} /\left(\rho_{\mathrm{L}} \sigma d_{\mathrm{b}}\right)^{0.5}$, in the right side of Eq. [8] corresponds to the Ohnesorge number, $Z$. Therefore, $q_{0} / Q$ can be expressed by the Ohnesorge number. The correlation with the Ohnesorge number was obtained as follows. 


$$
q_{0} / Q=6.66 Z^{1.46} .
$$

The same manner gives the correlation with the Ohnesorge number for foam as follows.

$$
W_{\mathrm{f} 0} / Q=2.53 Z^{0.533} \text {. }
$$

Figure 9 shows the comparison of the experimental dimensionless volumetric flow rates and the calculated ones for the nonfoaming and the foaming, respectively. It is clear that the correlative equations obtained in this study gives good approximation as shown in figure 9. Eqs. [9] and [10] fit the data within an error of 30 and $35 \%$ for nonfoaming and foaming, respectively.

Estimation of the enrichment ratio

To estimate the enrichment ratio, $E_{\mathrm{N}}$, and, $E_{\mathrm{F}}$, from Eqs. [1] and [2], $S_{\mathrm{b}} / q_{0}$ and $S_{\mathrm{b}} / W_{\mathrm{f} 0}$ were expressed from Eqs. [3], [9] and [10] by 
approximating the values of the exponent of the $Z$ for nonfoaming and foaming to 1.5 and 0.5 , respectively.

for nonfoaming:

$$
S_{\mathrm{b}} / q_{0}=0.645 U_{\mathrm{g}}^{-1 / 4}\left\{\delta(1-\varepsilon)^{4.65}\right\}^{1 / 4}(\Delta \rho g)^{1 / 6} \rho_{\mathrm{L}}{ }^{2 / 3} \mu_{\mathrm{L}}{ }^{-19 / 12} \sigma^{3 / 4} \text {, }
$$

for foaming:

$$
S_{\mathrm{b}} / W_{\mathrm{f} 0}=0.870 U_{g}^{-3 / 4}\left\{\varepsilon(1-\varepsilon)^{4.65}\right\}^{3 / 4}(\Delta \rho g)^{1 / 2} \mu_{\mathrm{L}}^{-3 / 4} \sigma^{1 / 4}
$$

$\Delta \rho$ in Eqs. [12] and [13] represents the difference of the density between liquid and gas. $E_{\mathrm{N}}$ and $E_{\mathrm{F}}$ values will be estimated from Eqs. [1], [2], [12] and [13] and appropriate parameters. Figures 10 and 11 show the comparison of the experimental values of $E_{\mathrm{N}}$ and $E_{\mathrm{F}}$ and the calculated ones estimated from Eqs. [1], [2], [12] and [13] for the nonfoaming (CV and HA in figure 10) and the foaming (HB and OA in figure 11). The adsorption parameters, $K$ and $\gamma$, used in calculation of $E_{\mathrm{N}}$ and $E_{\mathrm{F}}$ are summarized in Table 1. The both experimental and calculated values were in good agreement for the nonfoaming and the foaming. Eqs. [12] and [13] 
emphasize the influence of the liquid properties and the operating variables on $S_{\mathrm{b}} / q_{0}$ and $S_{\mathrm{b}} / W_{\mathrm{f} 0}$. To enlarge the enrichment ratio, the value of $S_{\mathrm{b}} / q_{0}$ and $S_{\mathrm{b}} / W_{\mathrm{f} 0}$ will be larger. Superficial gas velocity, the liquid viscosity and the surface tension particularly play an important role in the enrichment ratio. 


\section{CONCLUSIONS}

The influences of the liquid properties and the operating variables on the enrichment ratio, $E_{\mathrm{N}}$, in nonfoaming adsorptive bubble separation and $E_{\mathrm{F}}$ in foam separation were studied. The small change in the surface tension and the liquid viscosity were greatly influenced on the gas holdup, $\varepsilon$, the intrinsic volumetric flow rate, $q_{0}$, of the droplets at the liquid-atmosphere interface and $W_{\mathrm{f} 0}$ of the liquid in foam at the liquid-foam interface.

The dimensionless volumetric flow rate, $q_{0} / Q$ and $W_{\mathrm{fo}} / Q$, could be correlated with the Ohnesorge number: $q_{0} / Q=6.66 Z^{1.46}$ within an error of $30 \%$ for nonfoaming and $W_{\mathrm{f} 0} / Q=2.53 Z^{0.533}$ within an error of $35 \%$ for foaming by the dimensional correlation in the present study.

The enrichment ratio, $E_{\mathrm{N}}$, and $E_{\mathrm{F}}$, can be estimated from Eqs. [1], [2] and the dimensionless correlation. A good agreement of the experimental and the calculated values was obtained for nonfoaming and foaming. $E_{\mathrm{N}}$, and $E_{\mathrm{F}}$ were mainly affected by superficial gas velocity, the liquid viscosity and the surface tension in nonfoaming and foaming adsorptive bubble separation techniques. 
Further studies are required for the more broad range of the liquid properties and operating variables to verify the obtained correlative equations in the present study. 


\section{ACKNOWLEDGEMENTS}

The authors gratefully acknowledge Messrs. T. Hayashi, K. Koshimura, K. Shirahama, K. Ranba, N. Inoue, T. Senga, and S. Shibata and Misses C. Satoh and A. Fujii, former students of Department of Chemistry, Faculty of Fisheries, Hokkaido University, for their helps and efforts in the experiments. A part of this study was supported financially by the Grant-in-Aids for Encouragement of Young Scientists (No. 06760184, 1993-1994), The Ministry of Education, Science and Culture, Japan. 


\section{APPENDIX 1}

\section{NOTATION}

Roman symbol

$A \quad=$ a cross sectional area of bubble column $\quad\left[\mathrm{m}^{2}\right]$

Bo = Bond number $\left(=\left(\rho_{\mathrm{L}}-\rho_{\mathrm{G}}\right) d_{\mathrm{b}}{ }^{2} g^{2} / \sigma\right)$

$\mathrm{Ca}=$ Capillary number $\left(=\mu_{\mathrm{L}} v_{\mathrm{b}} / \sigma\right) \quad[-]$

$C_{\mathrm{i}} \quad=$ initial concentration of bulk liquid in bubble column $\quad\left[\mathrm{kg} / \mathrm{m}^{3}\right]$

$C_{\mathrm{b}} \quad=$ concentration of bulk liquid at equilibrium

in bubble column $\quad\left[\mathrm{kg} / \mathrm{m}^{3}\right]$

$C_{\mathrm{f} 0}=$ concentration of the liquid in foam within bubble column $\left[\mathrm{kg} / \mathrm{m}^{3}\right]$

$C_{\mathrm{tr}} \quad=$ concentration of the droplets $\quad\left[\mathrm{kg} / \mathrm{m}^{3}\right]$

$d_{\mathrm{b}} \quad=$ the average bubble diameter defined by Eq. [4] [m]

$E_{\mathrm{N}} \quad=$ the enrichment ratio, $C_{\mathrm{tr}} / C_{\mathrm{i}}$, defined by Eq. [1] [- ]

$E_{\mathrm{F}} \quad=$ the enrichment ratio, $C_{\mathrm{fo}} / C_{\mathrm{i}}$, defined by Eq. [2] [- ]

$\mathrm{Fr} \quad=$ Froude number $\left(=v_{\mathrm{b}}{ }^{2} /\left(g d_{\mathrm{b}}\right)\right) \quad[-]$

$g \quad=$ gravitational acceleration $\quad\left[\mathrm{m} / \mathrm{s}^{2}\right]$

$q_{0} \quad=$ the intrinsic volumetric flow rate of the droplets 
at the liquid-atmosphere interface within column $\quad\left[\mathrm{m}^{3} / \mathrm{s}\right]$

$Q \quad$ = volumetric flow rate of inlet gas

$\operatorname{Re} \quad=$ Reynolds number $\left(=d_{\mathrm{b}} v_{\mathrm{b}} \rho_{\mathrm{L}} / \mu_{\mathrm{L}}\right)$

$S_{\mathrm{b}} \quad=$ the production rate of bubble surface area

in the dispersion phase $\quad\left[\mathrm{m}^{2} / \mathrm{s}\right]$

$U_{\mathrm{g}} \quad$ superficial gas velocity $\quad[\mathrm{m} / \mathrm{s}]$

$v_{\mathrm{b}} \quad=$ the average rising velocity of bubbles defined by Eq. [5] [m/s]

We $\quad$ Weber number $\left(=v_{\mathrm{b}}^{2} \rho_{\mathrm{L}} / \sigma\right) \quad[-]$

$W_{\mathrm{f} 0} \quad=$ the intrinsic volumetric flow rate of the liquid in foam

at the liquid - foam interface within column $\quad\left[\mathrm{m}^{3} / \mathrm{s}\right]$

$Z \quad=$ Ohnesorge number $\left(=\mu_{\mathrm{L}} /\left(\rho_{\mathrm{L}} \sigma d_{\mathrm{b}}\right)^{0.5}\right) \quad[-]$

Greek symbol
$\varepsilon \quad=$ gas holdup
[-]
$\mu_{\mathrm{L}} \quad=$ liquid viscosity
$[\mathrm{kg} /(\mathrm{m} \mathrm{s})]$
$\rho_{\mathrm{G}} \quad=$ gas density
$\left[\mathrm{kg} / \mathrm{m}^{3}\right]$
$\rho_{\mathrm{L}} \quad=$ liquid density
$\left[\mathrm{kg} / \mathrm{m}^{3}\right]$
$\sigma \quad=$ surface tension
$[\mathrm{N} / \mathrm{m}]$ 


\section{REFERENCES}

1. Dorman, D. C., and Lemlich, R., Nature 207, 145 (1965).

2. Gautam, N. S., and Lemlich, R., Ind. Eng. Chem., Fund. 9(3), 350 (1970).

3. Lemlich, R., AIChE J. 12(4), 802 (1966).

4. Suzuki, A., Maruyama, H., Seki, H., and Hayashi, T., J. Chem. Eng. Jpn. 28(1), 115 (1995).

5. Suzuki, A., Maruyama, H., and Seki, H., J. Chem. Eng. Jpn. 29(5), 794 (1996).

6. Kubota, K., Hayashi, S. and Takubo, Y., Can. J. Chem. Eng. 57, 591 (1979).

7. Konduru, R., J. Chem. Eng. Japan 25, 548 (1992).

8. Dick, W. L. and Talbot, F. D., Ind. Eng. Chem. Fundamentals 10, 309 (1971).

9. Shirotsuka, T. and Ishiwata, M., Kagaku Kougaku 37, 397 (1973).

10. Hartland, S., and Barber A. D., Trans. Inst. Chem. Eng. 52, 43 (1974).

11. Desai, D., and Kumar, R., Chem. Eng. Sci. 38, 1525 (1983). 
12. Maruyama, H., Suzuki, A., and Seki, H., J. Colloid. Interface. Sci. 224(1), 76 (2000).

13. Lowry, O. H., Rowebrough, N. J., Farr, A. L., and Randall, R. J., J. Biol. Chem. 193, 265 (1951).

14. Allen, H. S., Phil. Mag. 50, 323 (1900).

15. Lewis, W. K., Gilliland, E. R., and Bauer, W. C., Ind. Eng. Chem. 41(6), 1104 (1949). 


\section{FIGURE AND TABLE CAPTIONS}

FIG. 1. Schematic diagram of mass balance of surface-active substance between (a) liquid in bulk and that in foam bed in foam separation and (b) liquid in bulk and that in droplet in nonfoaming adsorptive bubble separation.

FIG. 2. Schematic drawing of experimental setup for measuring volumetric flow rate, $q_{0}$, of droplet in nonfoaming adsorptive bubble separation.

FIG. 3. Detail drawing of droplet collector for determining the concentration, $C_{\mathrm{tr}}$, of droplet in nonfoaming adsorptive bubble separation.

FIG. 4. Schematic drawing of experimental setup for measuring the volumetric flow rate, $W_{\mathrm{f} 0}$, and the concentration, $C_{\mathrm{f} 0}$, of the liquid in foam within the column in foam separation. 
FIG. 5. Influences of superficial gas velocity and glycerin concentration on the intrinsic volumetric flow rate, $q_{0}$, of the droplets and gas holdup, $\varepsilon$.

FIG. 6. Influences of superficial gas velocity and SDBS concentration on the intrinsic volumetric flow rate, $W_{\mathrm{f} 0}$, of the liquid in foam and gas holdup, $\varepsilon$.

FIG. 7. Change in (a) the intrinsic volumetric flow rate of the droplets, $q_{0}$, and the liquid in foam, $W_{\mathrm{f} 0}$, and (b) gas holdup, $\varepsilon$, with surface tension. Symbols; $\bigcirc: \mathrm{C} 10\left(U_{\mathrm{g}}=5.37 \times 10^{-4} \mathrm{~m} / \mathrm{s}, \mathrm{G} 4\right.$ filter $), \triangle: 1 \mathrm{wt} \% \mathrm{NaCl} a q\left(U_{\mathrm{g}}\right.$ $=5.37 \times 10^{-4} \mathrm{~m} / \mathrm{s}$, G4 filter), $\diamond: \mathrm{OA}\left(\mathrm{pH} 4.6, U_{\mathrm{g}}=5.37 \times 10^{-4} \mathrm{~m} / \mathrm{s}, \mathrm{G} 4\right.$ filter), $\square: \mathrm{CV}\left(U_{\mathrm{g}}=5.37 \times 10^{-4} \mathrm{~m} / \mathrm{s}, \mathrm{G} 4\right.$ filter$), \quad$ : SDS $\left(U_{\mathrm{g}}=5.37 \times 10^{-4} \mathrm{~m} / \mathrm{s}, \mathrm{G} 3\right.$ filter), $\boldsymbol{\Delta}$ : SDBS $\left(U_{\mathrm{g}}=5.37 \times 10^{-4} \mathrm{~m} / \mathrm{s}\right.$, G4 filter $)$.

FIG. 8. Change in (a) the intrinsic volumetric flow rate of the droplets, $q_{0}$, and the liquid in foam, $W_{\mathrm{f} 0}$, and (b) gas holdup, $\varepsilon$, with liquid viscosity. Symbols; $\bigcirc$ : SDBS $\left(U_{\mathrm{g}}=5.37 \times 10^{-4} \mathrm{~m} / \mathrm{s}\right.$, G4 filter), $\triangle$ : OA $\left(\mathrm{pH} 4.6, U_{\mathrm{g}}=\right.$ 5.37 $\times 10^{-4} \mathrm{~m} / \mathrm{s}$, G4 filter), $\diamond:$ HB (pH 6.0, $U_{\mathrm{g}}=5.37 \times 10^{-4} \mathrm{~m} / \mathrm{s}, \mathrm{G} 4$ filter), 
$\square$ : OA (pH 6.0, $U_{\mathrm{g}}=5.37 \times 10^{-4} \mathrm{~m} / \mathrm{s}, \mathrm{G} 4$ filter $)$, O Glycerin $\left(U_{\mathrm{g}}=\right.$ $5.37 \times 10^{-4} \mathrm{~m} / \mathrm{s}$, G4 filter).

FIG. 9. Comparison of the experimental values of $q_{0} / Q$ and $W_{\mathrm{fo}} / Q$ with the calculated ones for (a) nonfoaming and (b) foaming as a function of the Ohnesorge number, $Z$. Symbols are shown in each figure.

FIG. 10. Comparison of the experimental values of the enrichment ratio, $E_{\mathrm{N}}$, with the calculated ones (solid lines) for crystal violet (CV) and humic acid (HA).

FIG. 11. Comparison of the experimental values of the enrichment ratio, $E_{\mathrm{F}}$, with the calculated ones for (a) ovalbumin and (b) hemoglobin.

TABLE 1. Adsorption Parameters of Estimation for $E_{\mathrm{N}}$ and $E_{\mathrm{F}}$. 


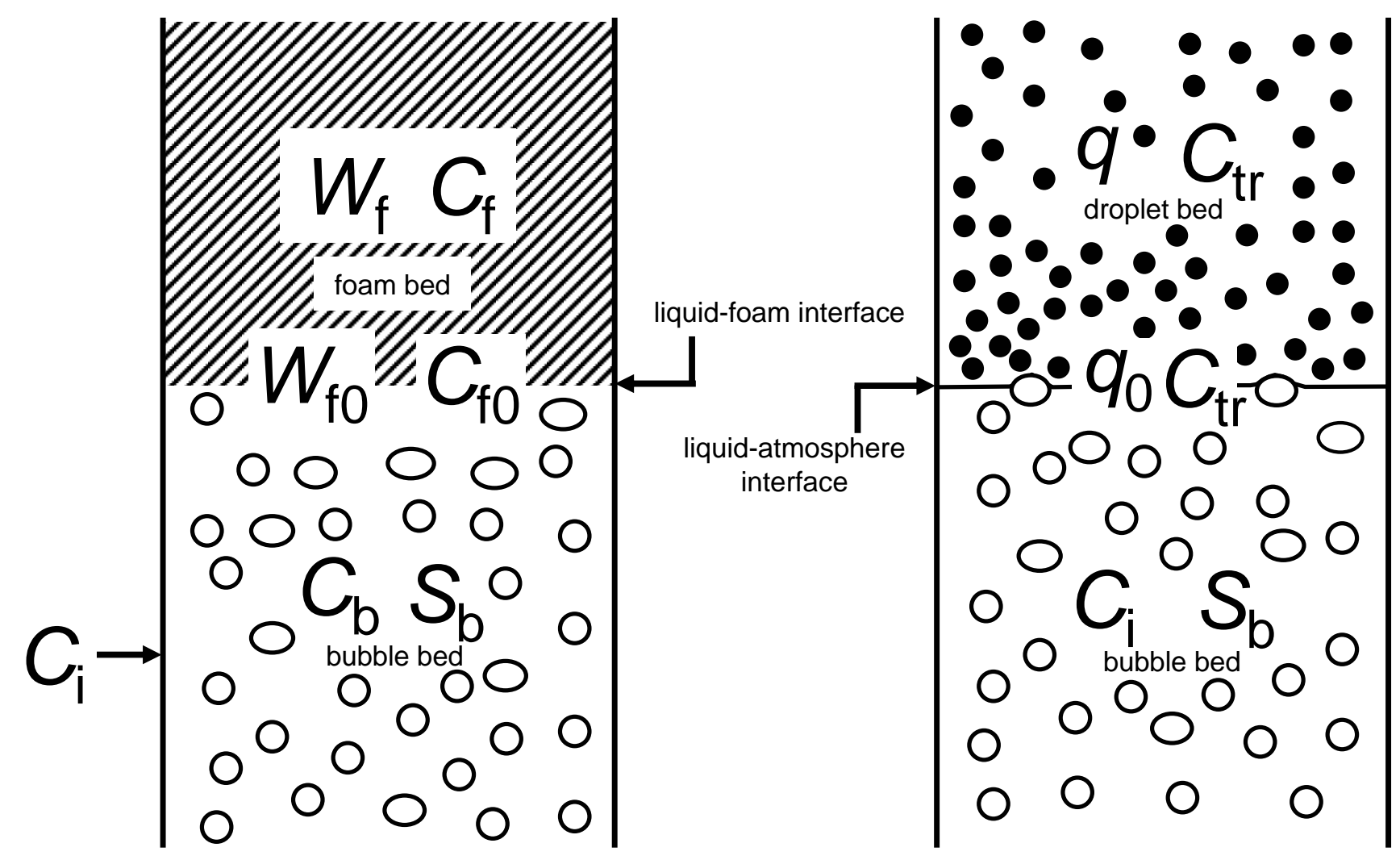

(a) Foam separation column

(b) nonfoaming adsorptive bubble separation column

FIG. 1. Schematic diagram of mass balance of surface-active substance between (a) liquid in bulk and that in foam bed in foam separation and (b) liquid in bulk and that in droplet in nonfoaming adsorptive bubble separation. 


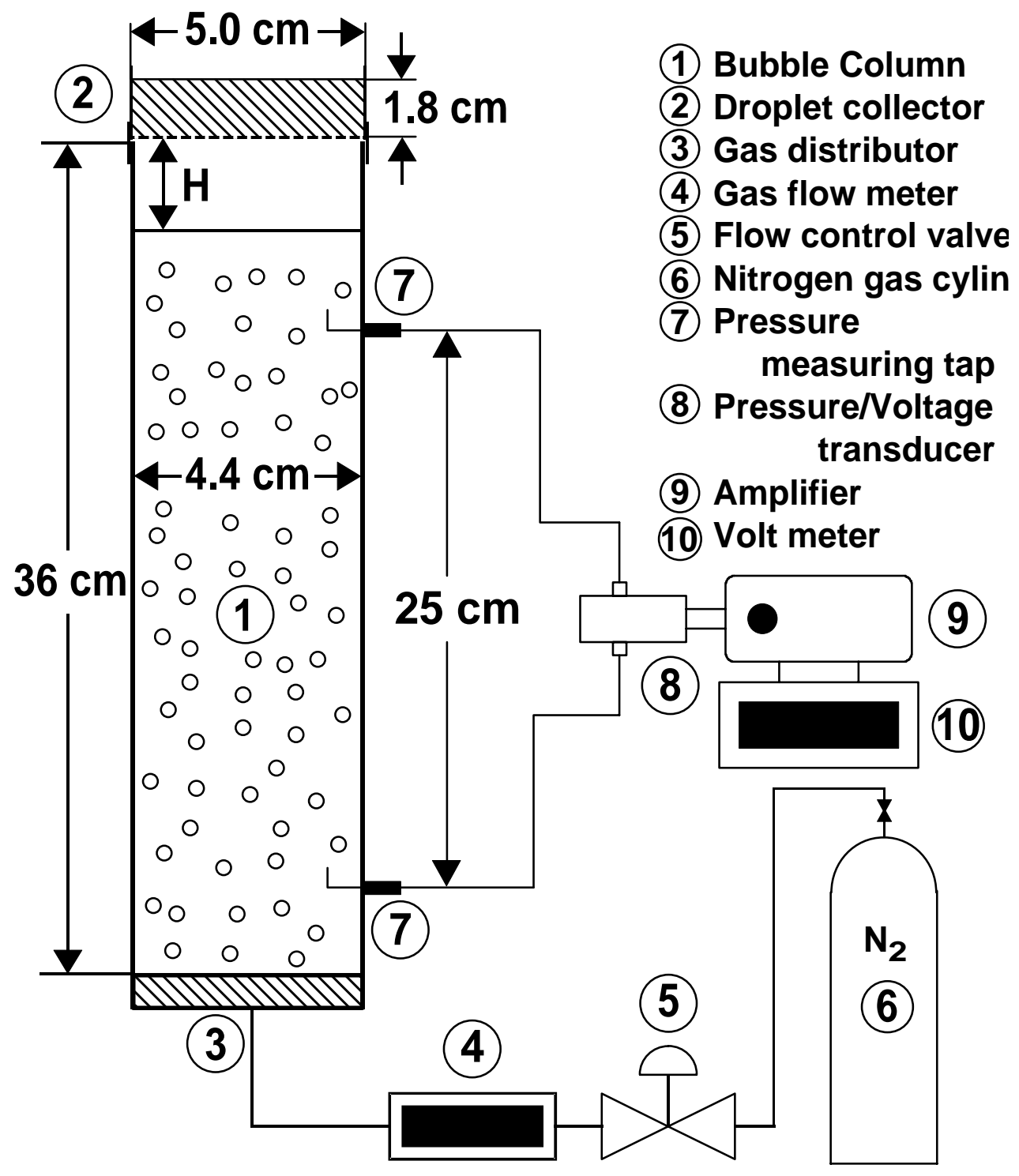

FIG. 2. Schematic drawing of experimental setup for measuring volumetric flow rate, $q$, of droplet in nonfoaming adsorptive bubble separation. 


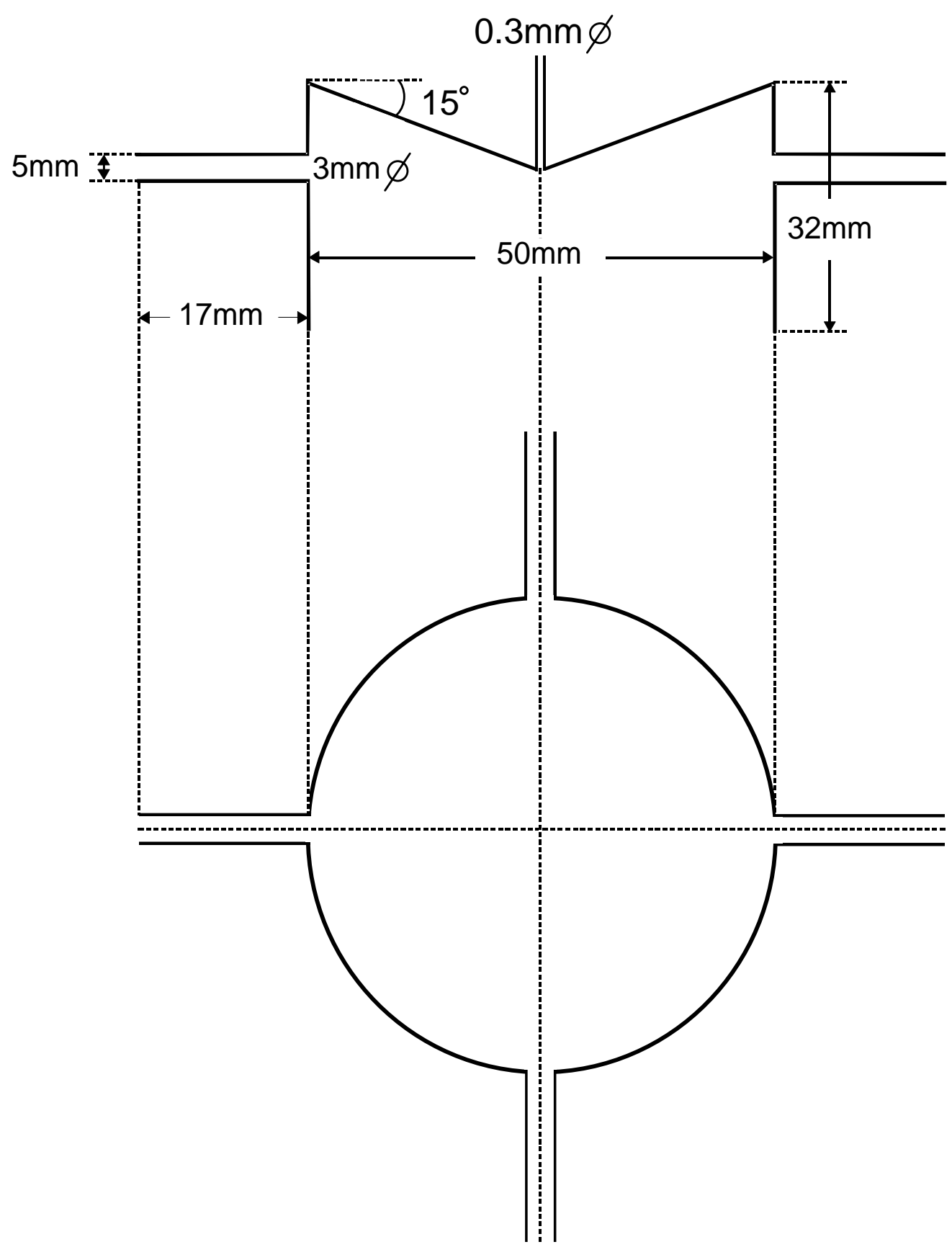

FIG. 3. detail drawing of droplet collector for determining the concentration, $C_{\mathrm{tr}}$, of droplet in nonfoaming adsorptive bubble separation experiment. 


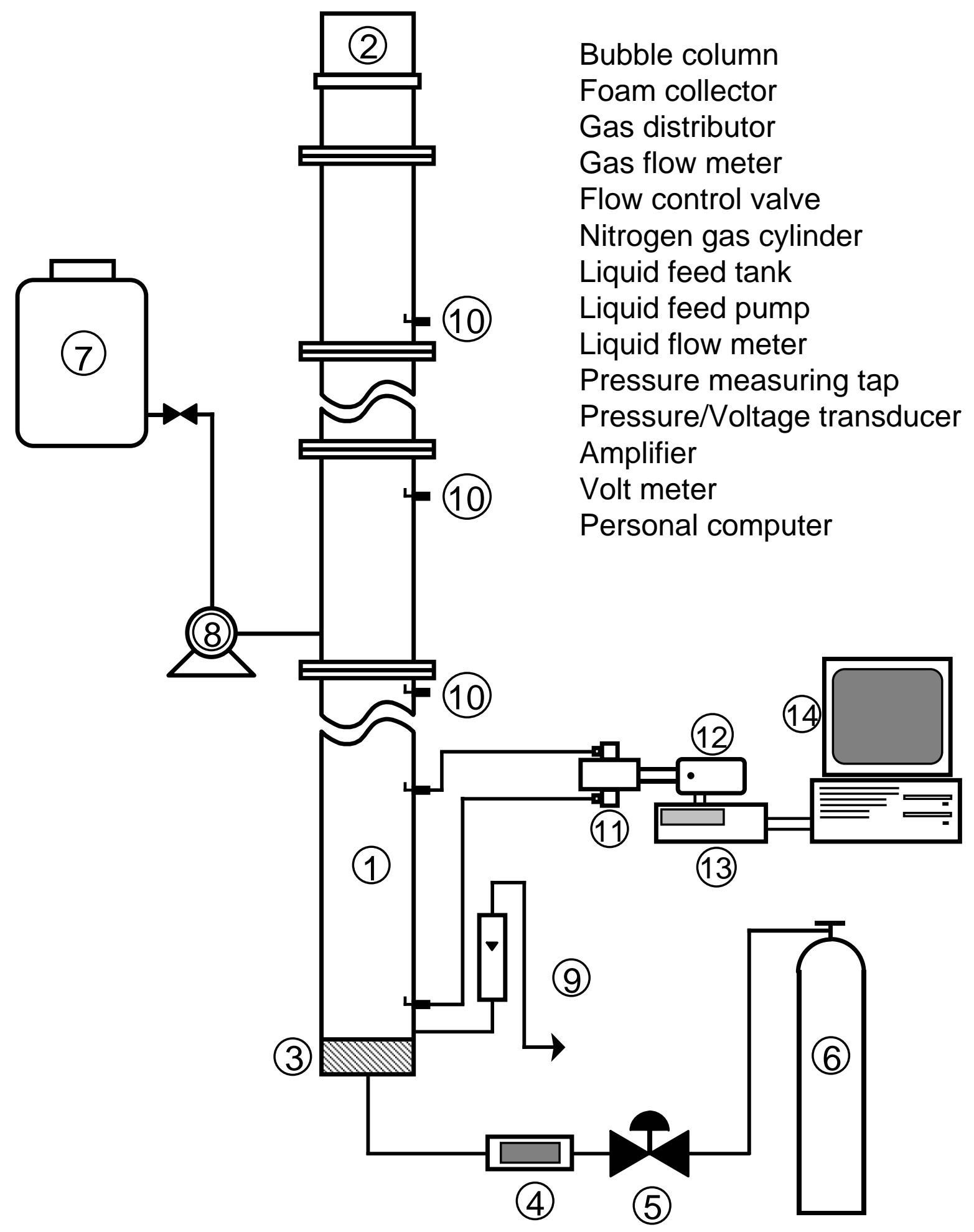

FIG. 4. Schematic drawing of experimental setup for continuous foam separation. 


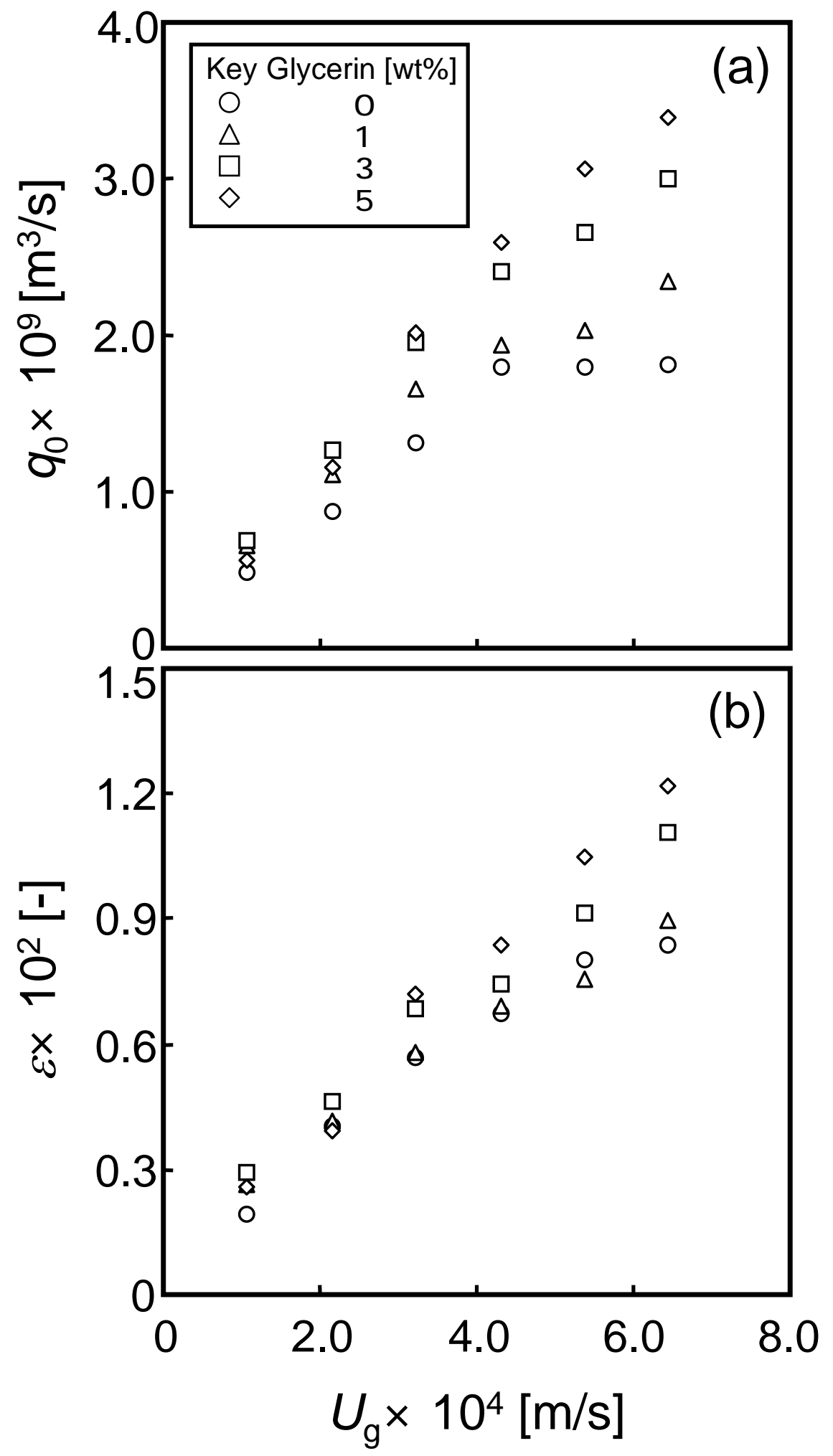

FIG. 5. Influences of superficial gas velocity and glycerin concentration on the intrinsic volumetric flow rate of the droplets, $q_{0}$, and gas holdup, $\varepsilon$. 


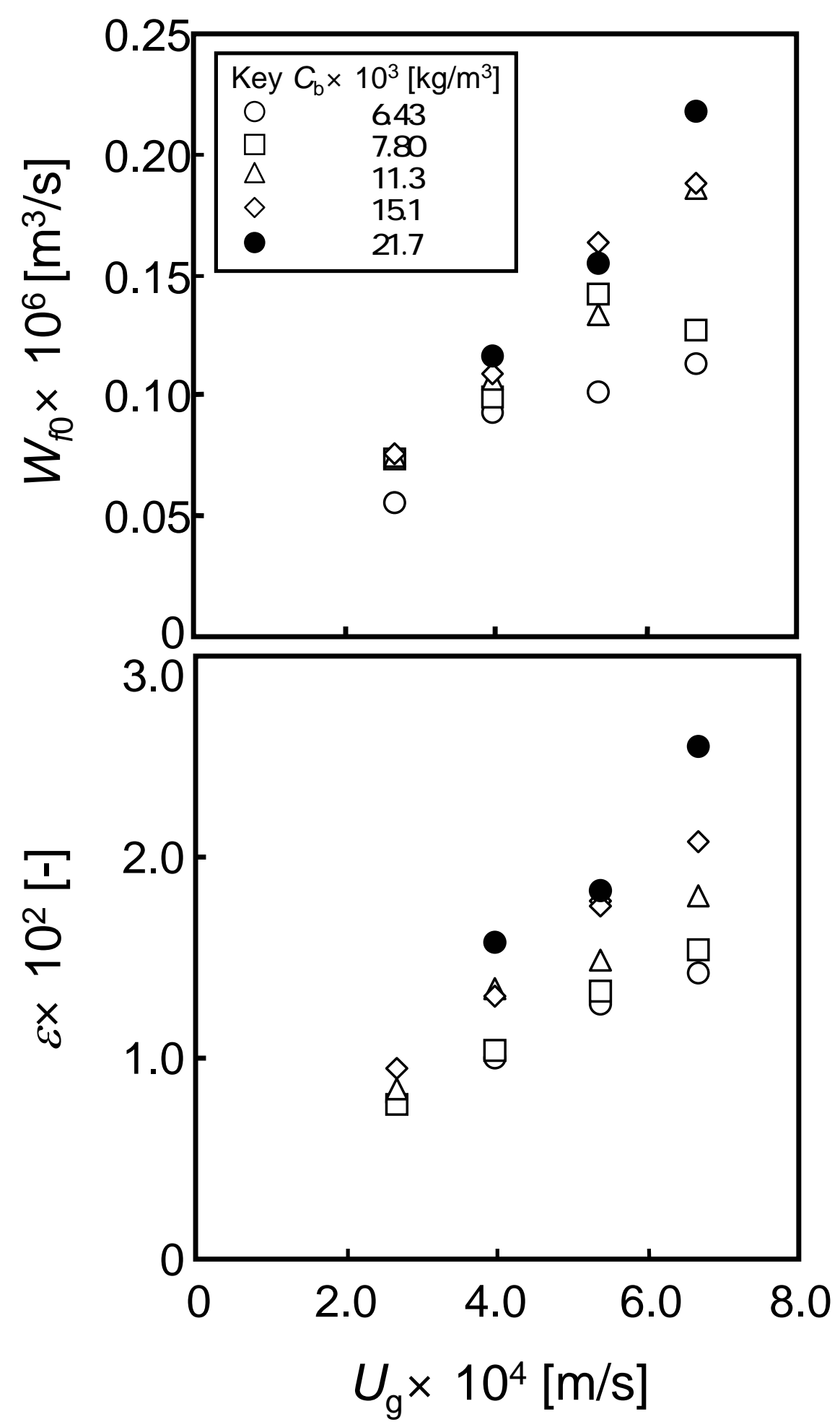

FIG. 6. Influences of superficial gas velocity and SDBS concentration on the intrinsic volumetric flow rate, $W_{\mathrm{f} 0}$, of the liquid in foam and gas holdup, $\varepsilon$. 


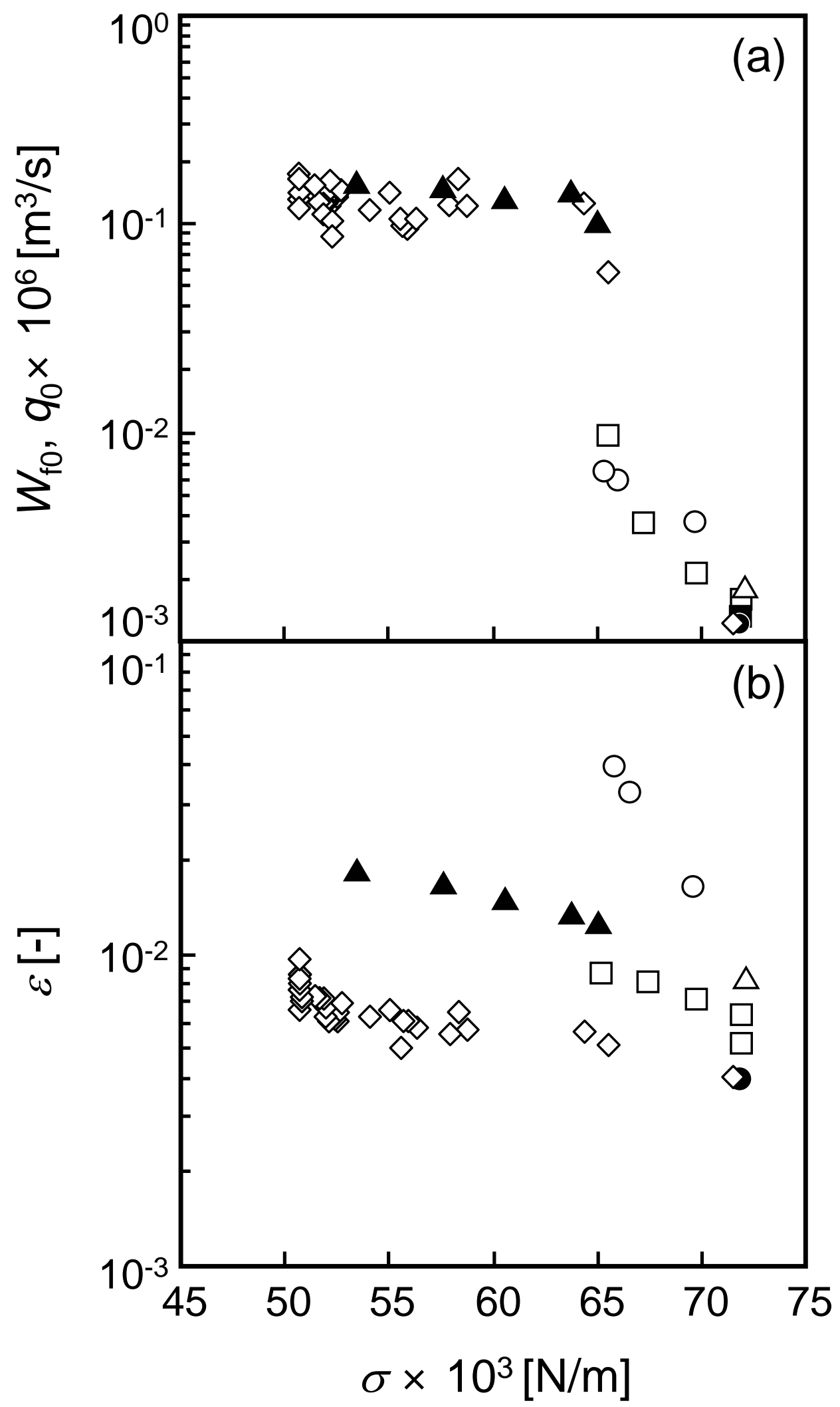

FIG. 7. Change in (a) the intrinsic volumetric flow rate of the droplets, $q_{0}$, and the liquid in foam, $W_{\mathrm{f} 0}$, and (b) gas holdup, $\varepsilon$, with surface tension. Symbols; $\bigcirc$ : C10 $\left(U_{\mathrm{g}}=5.37 \times 10^{-4} \mathrm{~m} / \mathrm{s}\right.$, G4 filter $), \triangle: 1 \mathrm{wt} \% \mathrm{NaCl} a q\left(U_{\mathrm{g}}=5.37 \times 10^{-4} \mathrm{~m} / \mathrm{s}, \mathrm{G} 4\right.$ filter), $\diamond:$ OA (pH 4.6, $U_{\mathrm{g}}=5.37 \times 10^{-4} \mathrm{~m} / \mathrm{s}, \mathrm{G} 4$ filter $), \square: \mathrm{CV}\left(U_{\mathrm{g}}=5.37 \times 10^{-4}\right.$ $\mathrm{m} / \mathrm{s}$, G4 filter), $\mathrm{O}$ : SDS $\left(U_{\mathrm{g}}=5.37 \times 10^{-4} \mathrm{~m} / \mathrm{s}\right.$, G3 filter), $\boldsymbol{\Delta}: \operatorname{SDBS}\left(U_{\mathrm{g}}=\right.$ $5.37 \times 10^{-4} \mathrm{~m} / \mathrm{s}$, G4 filter). 


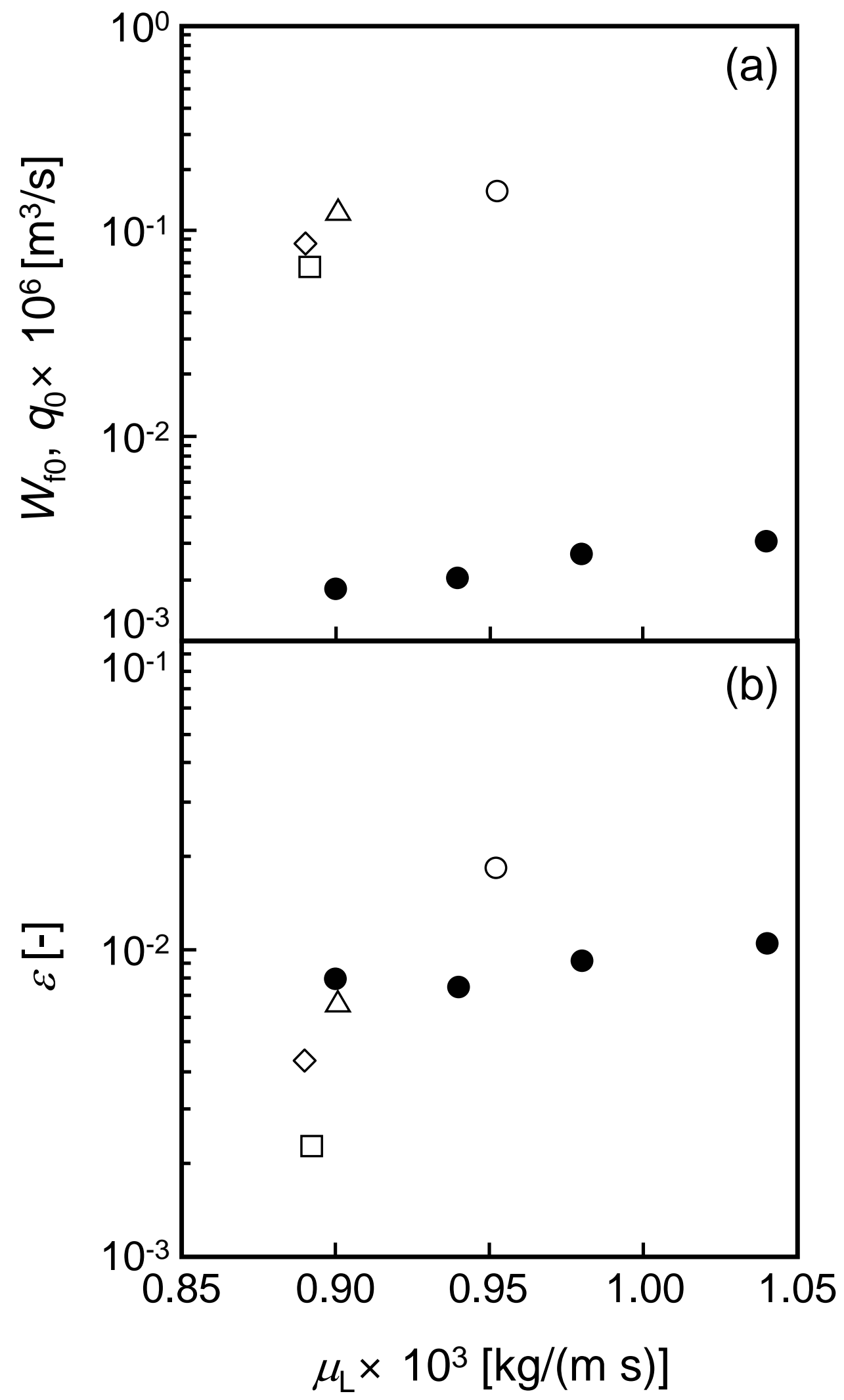

FIG. 8. Change in (a) the intrinsic volumetric flow rate of the droplets, $q_{0}$, and the liquid in foam, $W_{\mathrm{f} 0}$, and (b) gas holdup, $\varepsilon$, with liquid viscosity. Symbols; $\bigcirc$ : SDBS $\left(U_{\mathrm{g}}=5.37 \times 10^{-4} \mathrm{~m} / \mathrm{s}\right.$, G4 filter), $\triangle$ : OA (pH 4.6, $U_{\mathrm{g}}=$ $5.37 \times 10^{-4} \mathrm{~m} / \mathrm{s}, \mathrm{G} 4$ filter), $\diamond: \mathrm{HB}\left(\mathrm{pH} 6.0, U_{\mathrm{g}}=5.37 \times 10^{-4} \mathrm{~m} / \mathrm{s}\right.$, G4 filter), $\square$ : OA (pH 6.0, $U_{\mathrm{g}}=5.37 \times 10^{-4} \mathrm{~m} / \mathrm{s}$, G4 filter), : Glycerin $\left(U_{\mathrm{g}}=5.37 \times 10^{-4} \mathrm{~m} / \mathrm{s}\right.$, G4 filter). 


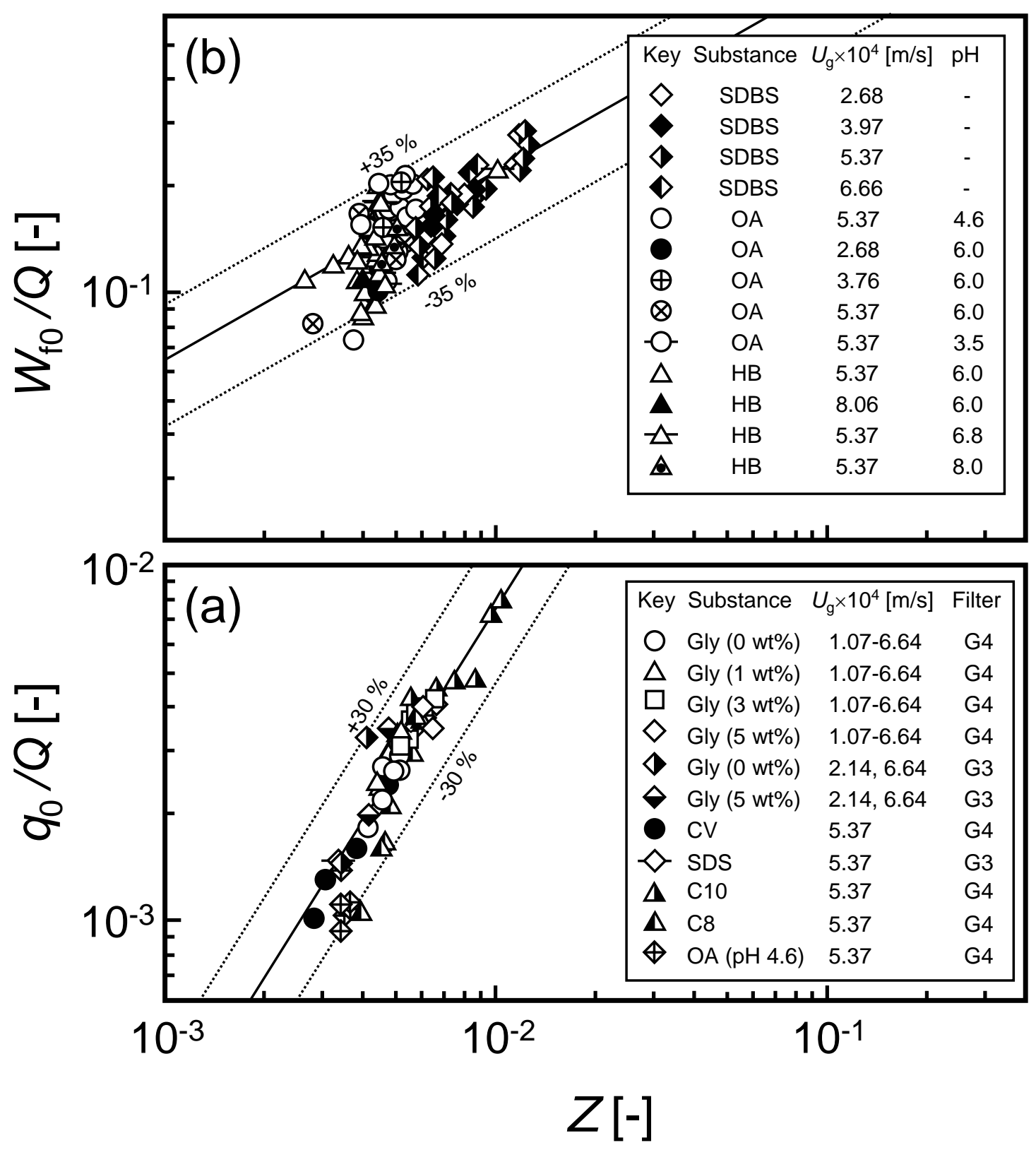

FIG. 9. Comparison of the experimental values of $q_{0} / Q$ and $W_{\mathrm{fo}} / Q$ with the calculated ones for (a) nonfoaming and (b) foaming as a function of the Ohnesorge number, $Z$. Symbols are shown in each figure. 


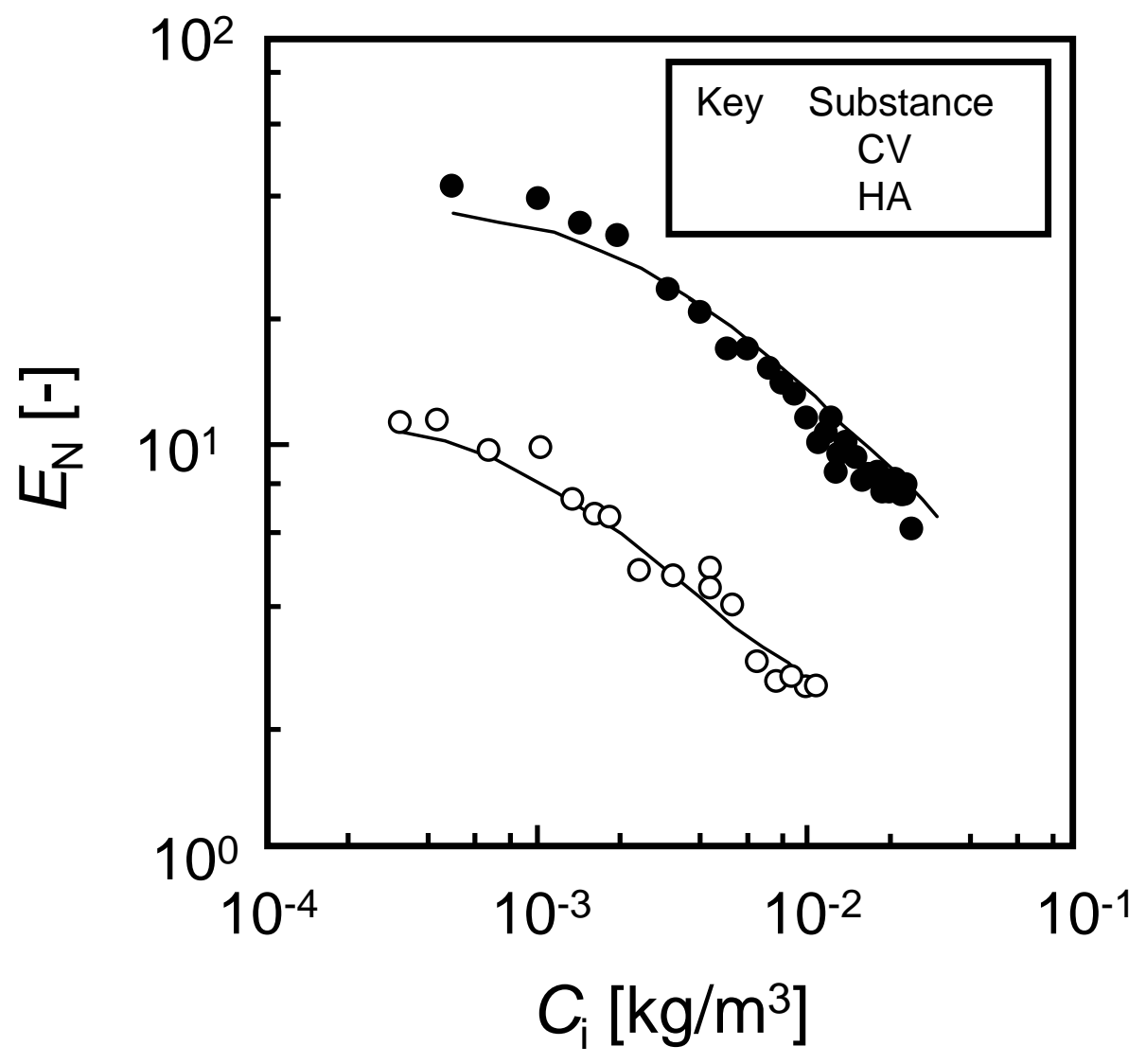

FIG. 10. Comparison of the experimental values of the enrichment ratio, $E_{\mathrm{N}}$, with the calculated ones (solid lines) for crystal violet (CV) and humic acid (HA). 


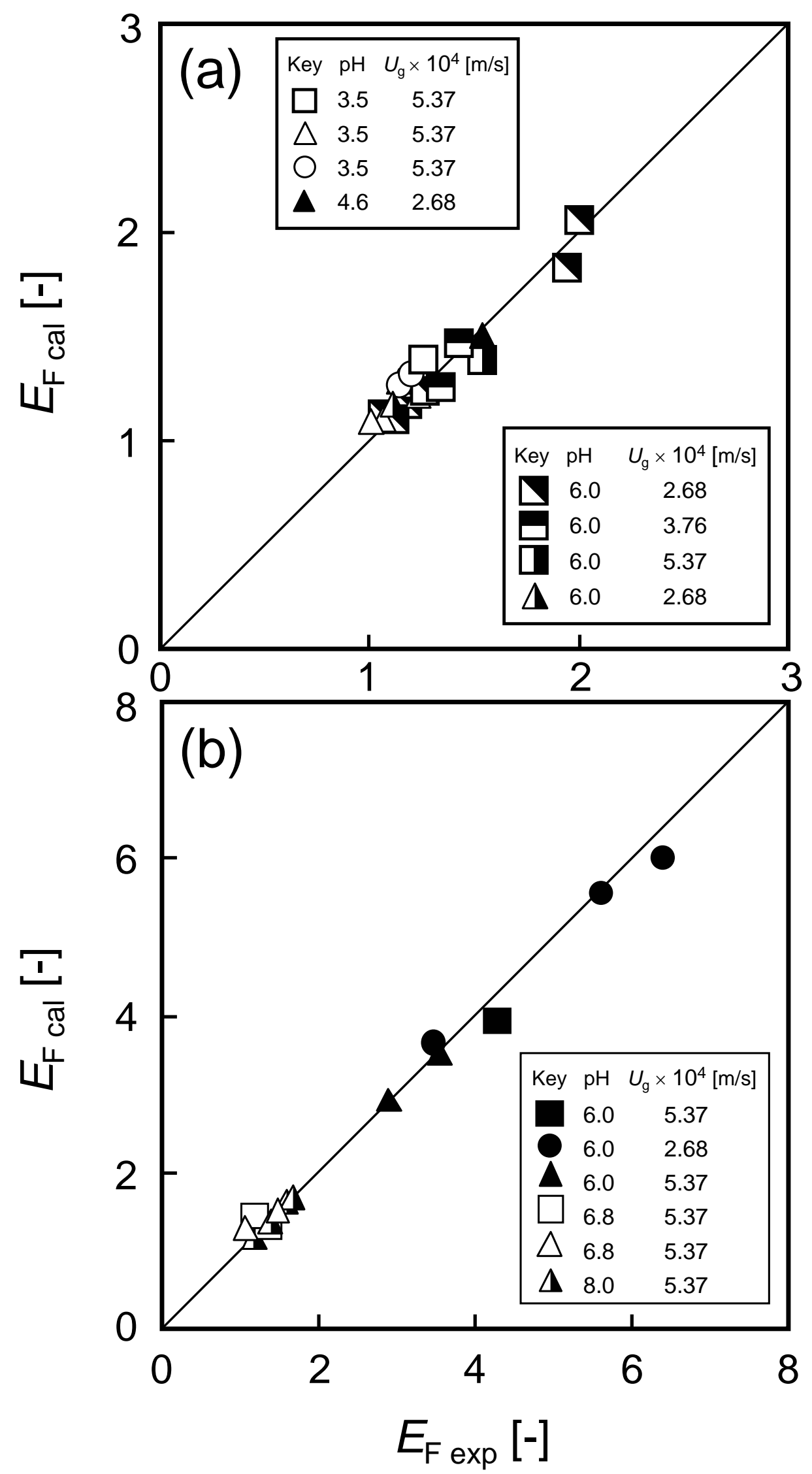

FIG. 11. Comparison of the experimental values of the enrichment ratio, $E_{\mathrm{F}}$, with the calculated ones for (a) ovalbumin and (b) hemoglobin. 
TABLE 1. Adsorption Parameters for Estimation for $E_{\mathrm{N}}$ and $E_{\mathrm{F}}$.

\begin{tabular}{cccc}
\hline & $\mathrm{pH}$ & $\gamma\left[\mathrm{kg} / \mathrm{m}^{2}\right]$ & $K\left[\mathrm{~m}^{3} / \mathrm{kg}\right]$ \\
\hline $\mathrm{OA}^{\mathrm{a}}$ & 3.5 & $2.30 \times 10^{-6}$ & $3.94 \times 10^{2}$ \\
& 4.6 & $3.39 \times 10^{-6}$ & $1.01 \times 10^{3}$ \\
& 6.0 & $1.92 \times 10^{-6}$ & $8.72 \times 10^{2}$ \\
\cline { 2 - 4 } $\mathrm{HB}^{\mathrm{a}}$ & 6.0 & $1.96 \times 10^{-6}$ & $6.52 \times 10^{3}$ \\
& 6.8 & $2.27 \times 10^{-6}$ & $5.88 \times 10^{2}$ \\
& 8.0 & $1.78 \times 10^{-6}$ & $1.27 \times 10^{3}$ \\
& & & \\
$\mathrm{CV}^{\mathrm{b}}$ & & $4.64 \times 10^{-9}$ & $6.74 \times 10^{2}$ \\
& & & $1.77 \times 10^{2}$ \\
$\mathrm{HA}^{\mathrm{b}}$ & & $5.24 \times 10^{-8}$ & \\
\hline
\end{tabular}

a: Ref. 12

b: Ref. 5 